\title{
Super-Insulating Gas-Filled Panels
}

\author{
Dariush Arasteh, Brent Griffith, and Stephen Selkowitz \\ Applied Science Division \\ Lawrence Berkeley Laboratory \\ University of California \\ Berkeley, California 94720
}

August 1990

This work was supported by the Assistant Secretary for Conservation and Renewable Energy, Office of Building Technologies, Building Systems and Materials Division of the U.S. Department of Energy under Contract No. DEAC03-76SF00098. 


\title{
Super-Insulating Gas-Filled Panels
}

\author{
Dariush Arasteh, Brent Griffith, and Stephen Selkowitz \\ Windows and Daylighting Group \\ Lawrence Berkeley Laboratory \\ Berkeley, CA 94720
}

August 1990

\begin{abstract}
This paper presents the design, material characteristics, and thermal performance of a new insulating material. Development of this material is motivated by the need for non-CFC based high performance insulations with applications for refrigerator/freezer and building walls. This super insulating gas filled panel technology achieves $R$-values of between $8 \mathrm{hr}-\mathrm{ft}^{2}-\mathrm{F} / \mathrm{Btu}$ per inch and $15 \mathrm{hr}-\mathrm{ft}^{2}$. $\mathrm{F} /$ Btu per inch (one to two times that of CFC blown foams and two fo four times that of fiberglass insulations) at estimated costs of $\$ 0.40-\$ 1.50 / \mathrm{in}_{-1 \mathrm{ft}}{ }^{2}$. Prototypes have been built using commercially available materials and components, tested by the developers, and sent to an independent laboratory for independent thermal performance testing.
\end{abstract}

\section{Introduction}

Recent research efforts at the Windows and Daylighting Group at Lawrence Berkeley Laboratory have focused on the development of low to moderate cost super insulating gas filled panels. Development of this and other high-performance insulating materials is motivated by the search for replacements for CFC blown foams $[1,2]$. CFC blown foams are the best commercially available insulating materials ( $R 7 \mathrm{hr}-\mathrm{ft}^{2}-\mathrm{F} / \mathrm{Btu}$ ). However, national goals to reduce the use of CFC's and increase the energy efficiencies of appliances and buildings require an alternative high perforinance insulating material.

Super insulating gas filled panels use commercially available technologies to simultaneously minimize radiative, conductive, and convective heat transfer. These panels consist of several plane parallel sheets of metallized gas-impermeable polymer films (0.001-0.005 inches thick). These low-emissivity metallized sheets virtually eliminate radiative heat transfer. As shown in Figure 1, the sheets are structured to form an exterior skin; intermediate layers are used to create multiple low-conductivity gas-filled gaps. Because the enclosed volume is a gas at atmospheric pressure, these panels are self-supporting. The gas-fill is chosen to minimize conductive heat transfer given the costs and requirements of the specific application. Gap spacing is optimized for the gas fill chosen but usually varies between $0.25^{\prime \prime}$ and $0.50^{\prime \prime}$. Low-emittance baffles, constructed using crumpled 0.0005 
inch thick film placed in-between each set of parallel layers, minimize convection and further decrease radiation. Due to the thinness and relatively low conductivity of the sheet material, edge losses are insignificant. A schematic is shown in Figure 1. While the baffles used in prototypes to date and shown schematically in Figure 1 maintain the material's overall structure, the design presented here will not, by itself, enhance the structural rigidity of a freezer or refrigerator. Alternative gasfilled panel designs employing stronger baffles (i.e. st ructural honeycombs) and gasfilled panels used in conjunction with non-CFC blown foams are currently being studied for such applications. This material is the subject of a patent application by Lawrence Berkeley Laboratory.

\section{Performance and Cost Specifics}

Performance levels for these super-insulating gas filled panels vary from $\mathrm{R} 8 /$ in $\mathrm{R} 15 /$ in depending on the gas choser. Using a 95-100\% argon fill produces a lowcost moderately performing option as shown in Table 1. With a 95-100\% krypton fill, performance and cost both increase. For applications with required R-values in between the two options outlined in Table 1, mixtures of argon and krypton can be used; performances and costs are roughly linear with ratio changes.

Table 1: Performance Levels and Manufacturer's Cost Essimates

\begin{tabular}{|c|c|c|c|}
\hline \multirow{2}{*}{ Option } & \multirow{2}{*}{$\begin{array}{c}\text { R-value } \\
\operatorname{lrr}-\mathrm{ft}^{2}-\mathrm{F} / \text { Btu-in }\end{array}$} & \multirow{2}{*}{\multicolumn{2}{|c|}{$\left(\$ / \mathrm{ft}^{2}-\mathrm{in}\right) \quad \stackrel{\text { Estimated Costs }}{\left(\$ / \mathrm{ft}^{2}-\mathrm{R}\right)}$}} \\
\hline & & & \\
\hline Fiberglass[2] & 3.5 & $0.04-0.05$ & $0.01-0.015$ \\
\hline CFC Blown Foams[2] & 7 & $0.20-0.50$ & $0.03-0.07$ \\
\hline $\begin{array}{l}\text { Low Cost; Moderate } \\
\text { Performance Panels }\end{array}$ & 8 & $0.35-0.50$ & $0.04-0.06$ \\
\hline $\begin{array}{l}\text { Moderate Cost; High } \\
\text { Perfoimance Panels }\end{array}$ & 15 & $1.00-2.00$ & $0.07-0.13$ \\
\hline
\end{tabular}

\section{Research Results}

Over the last year, LBL researchers have built and tested several dozen prototypes. Prototype samples (typically $12^{\prime \prime} \times 12^{\prime \prime}$ ) are placed in a rigid CFC blown foam board (with a known resistance). A temperature difference is generated across the insulation by placing the foam board sample between ambient temperature and a cold chamber. An infrared imaging system is then used to compare warm side surface temperatures of the prototype to that of the surrounding foam. This setup is shown schematically in Figure 2. Warm side temperatures are directly correlated with thermal resistances; the warmer the room side surface temperature, the better the insulator. Such side by side testing allows for quick, visual, and accurate evaluation of prototype samples. A versatile post-processing system provides quantitative information on the prototypes. 
For example, Figure 3 shows an infrared image of the warm side of a 1 " thick sample of $\mathrm{CFC}$ blown foam with an insert containing a $1 "$ thick sample of an argon filled super insulating gas filled panel. The average warm side of the sample is $0.7 \mathrm{~F}$ warmer than the CFC blown foam, indicating a greater resistance to heat transfer. Based on this thermograph, the R-value of this sample is estimated at 8/in.

Similar experiments were performed on krypton filled panels. For example, infrared thermography and the cold chamber of Figure 2 were used to analyze a 0.80 " thick krypton filled sample set into an R10 foam board (equivalent to 1.4" of CFC Blown foam). The thin prototype super-insulating panel's average warm side surface temperature was slightly warmer than that of the thicker foam board, resulting in an estimated $\mathrm{R}$-value of $13 /$ in for this sample. The expected performance of this configuration is R15/in. Differences in measured and expected performance are attributed to uncertainties in the gas-filling process used and nonoptimized convective suppression layers.

In another experiment, half of a freezer door was left as manufactured (with 2.4 " of CFC blown foam); the other half was retrofitted with a $1.7^{\prime \prime}$ thick super-insulating panel. The infrared photo shows no significant difference (the resolution of our camera is $0.2 \mathrm{~F}$ ) between the warm side temperatures of both sides of the freezer door, indicating equal thermal resistances from both sides (see Figure 4). In a typical 20 cubic foot refrigerator/freezer, this change would increase the useable interior volume by $15 \%$, or, energy efficiencies could be improved, or both.

While infrared thermography is excellent for a quick comparison of the thermal performance of different specimens, it is not presently a developed technique to determine R-values. For this reason, several samples have been manufactured and sent to Oak Ridge National Laboratory for independent testing using a hot plate facility designed for measuring the R-values of materials. Results are expected this fall.

Materials and components used in the construction of these prototypes are all commercially available. Final commercial products would require routine optimizing of some of these materials. Samples to date have been built by hand. Preliminary investigations into mass production technologies indicate that existing processes and machinery from the packaging (specifically food) industries can easily be used to mass-produce a commercial insulation product.

\section{Conclusions and Future Work}

Preliminary efforts aimed at developing prototype super insulating gas filled panels indicate that such materials perform effectively and can be built at a reasonable cost using commercially available materials. Predicted performances of R8/in - R15/in have been validated with infrared thermography; heat flux measurements are in progress.

A continuing research effort is planned for the upcoming year. Materials and designs will be optimized to maximize thermal and long-term performance and costeffectiveness. Additional prototypes will be built, installed in refrigerator/freezer and building walls, and tested. Collaborative efforts with industry and building groups are planned. The small scale automated production of prototypes using one or more existing manufacturing technologies will be explored. 


\section{References}

[1] Potter, T. and Smith, L. "Assessment of the Cost-Effective Energy Conservation Potential of Advanced Refrigerator Insulation." ASHRAE Transactions, AT-90)-221.

[2] Rocky Mountain Institute. "The State of the Art: Appliances," Competitek, 1990. Snowmass, Colorado.

\section{Acknowledgements and Disclaimer}

The research reported here was funded, in part, by the California Institute for Energy Efficiency (CIEE), a research unit of the University of California.

Publication of research results does not iniply CIEE endorsement of or agreement with these findings, nor that of any CIEE sponsor.

This work was also supported by the Assistant Secretary for Conservation and Renewable Energy, Office of Building Technologies, Building Systems and Materials Division of the U.S. Depariment of Energy under Contract No. DEAC03-76SF000)8.

The authors also wish to thank their colleagues Fred Beck and Ian Sundly whose help in infrared thermography and sample preparation was invaluable.

Materials donated by M\&D Balloons Incorporated and Metallized Products Incorporated were used in the production of prototype samples. 


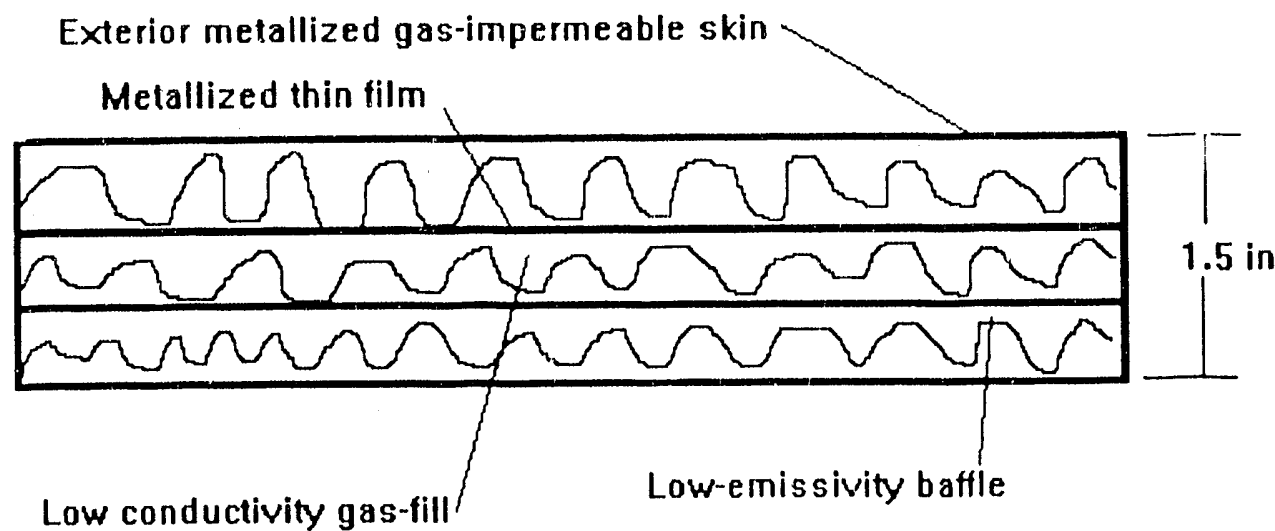

Figure 1: Schematic cross-section of super-insulating gas-filled panels.
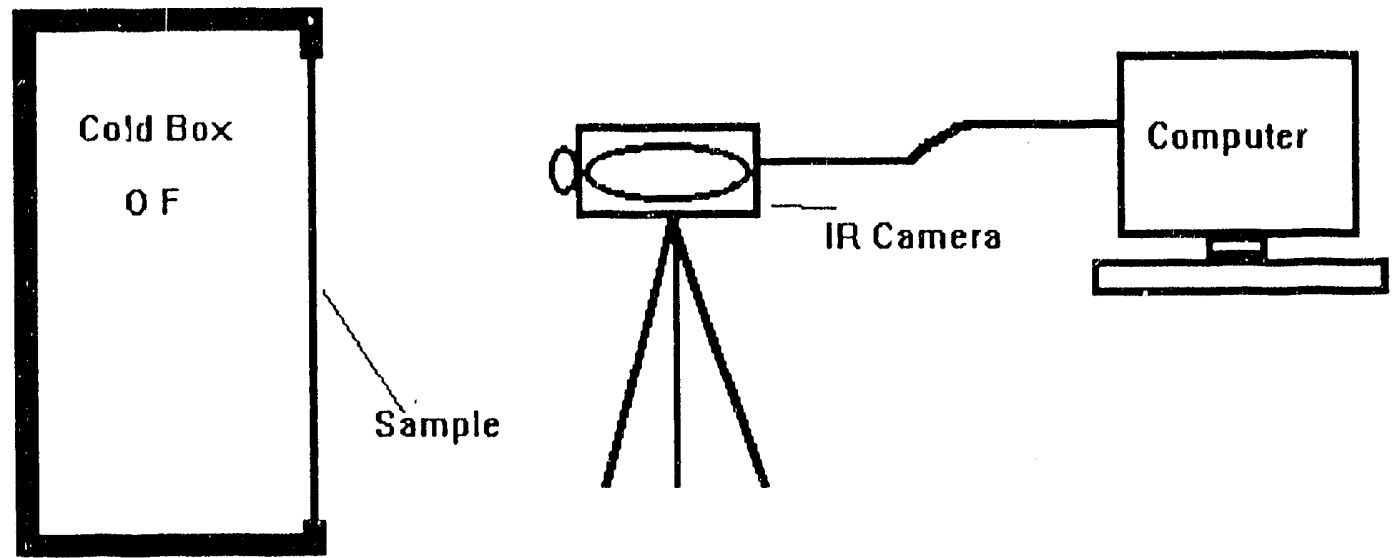

Figure 2: Schematic cross-section of infrared camera and cold box facility. The infrared camera records the warm side temperature distribution of a sample placed between the cold box and ambient. The closer the sample's (or part of the sample's) warm side temperature is to ambient, the better an insulator it is. A computer, attached to the infrared camera, allows for quick and versatile post-processing. 

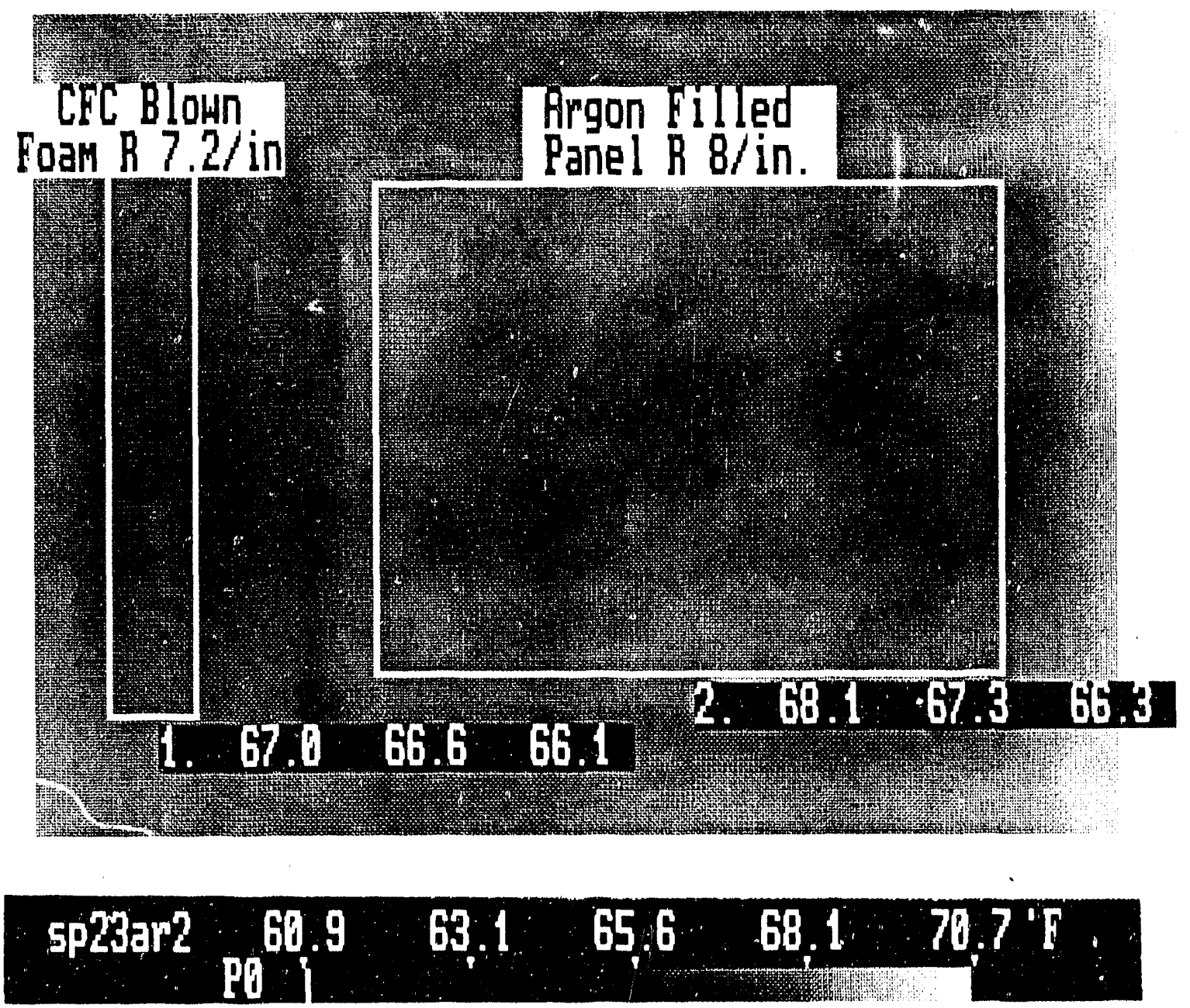

Figure 3: Infrared photo of the warm side of a 1" thick sample of CFC blown foam with an insert containing a 1 " thick sample of argon filled panels. The back of this panel faces a cold box at approximately $-1.5 \mathrm{~F}$; ambient temperature is approximately $71.6 \mathrm{~F}$. The warm side temperature of the CFC blown foam averages $66.6 \mathrm{~F}(\mathrm{max} 67.0 \mathrm{~F}$, min $66.1 \mathrm{~F}$ ) and the warm side of the LBL insulation averages $67.3 \mathrm{~F}(\mathrm{max} 68.1 \mathrm{~F}$, min $66.3 \mathrm{~F}$ ). In this figure, warmer areas are lighter and colder areas are darker. A temperature grey-scale is shown at the bottom of the figure. Since surface temperatures correspond to heat loss rates, a higher warm side temperatures implies a lower lieat loss rate. The $\mathrm{R}$-value of the panels shown here is estimated at $\mathrm{R} 8 /$ in; that of the $\mathrm{CFC}$ blown foam is $\mathrm{R} 7.2 / \mathrm{in}$. 


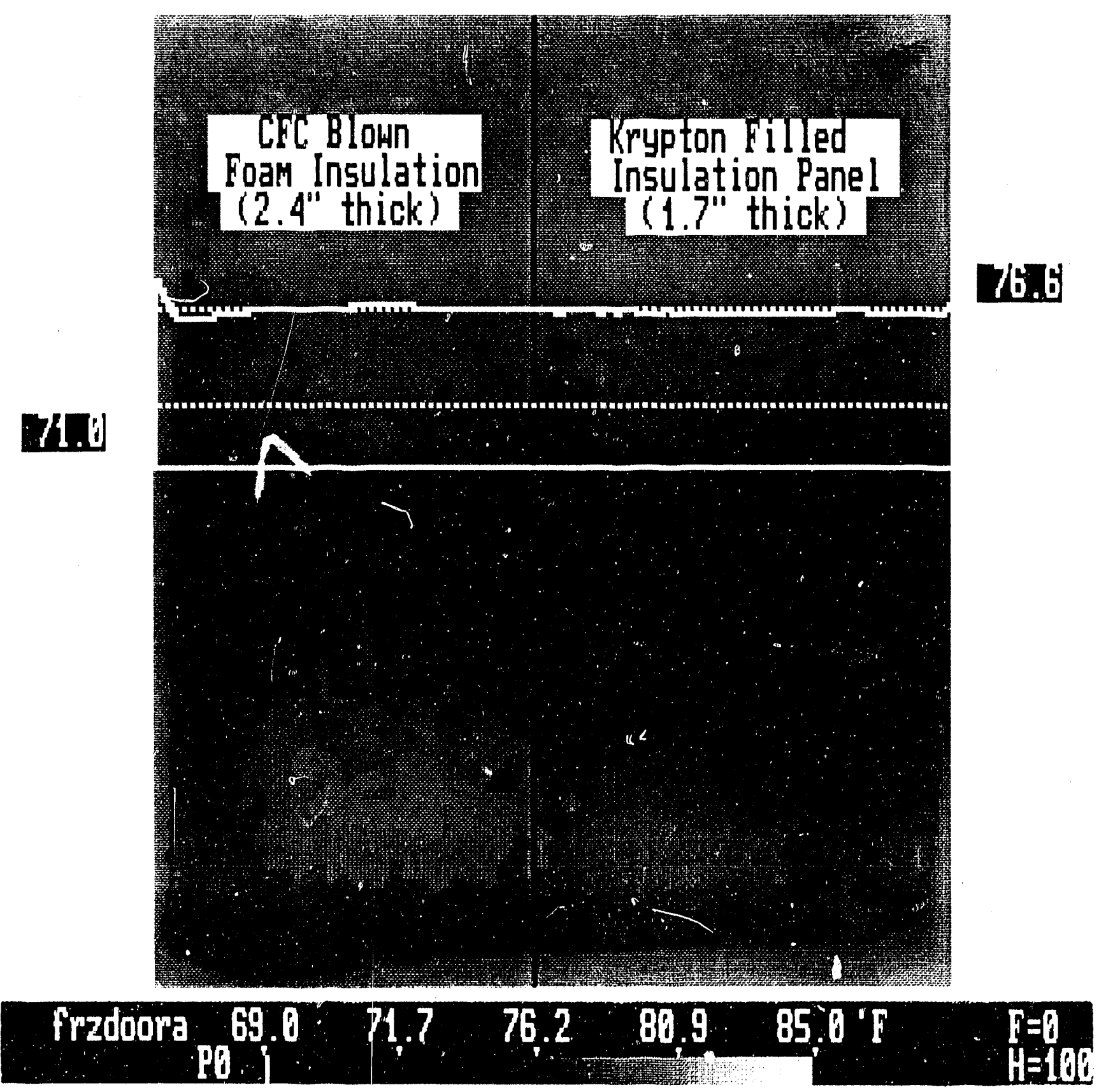

Figure 4: Infrared photo of the door on a real fre zer. The freezer is operating at about $-5 \mathrm{~F}$ with an ambient temperature of $80 \mathrm{~F}$. Hialf of the freezer door was left as manufactured (with $2.4^{\prime \prime}$ of CFC blown foam); the other half was retrofitted with $1.7^{\prime \prime}$ of krypton filled panels. In this figure, warmer areas are lighter and colder areas are darker. A temperature grey-scale is shown at the bottom of the figure. Since surface temperatures correspond to heat loss rates, a higher warm side temperatures implies a lower heat loss rate. The infrared photo shows no significant difference (the resolution of our camera is $(0.2 \mathrm{~F}$ ) between the warm side temperatures of both sides of the freezer door, indicating that 1.7" inches of gas-filled panels are as good an insulator as 2.4 " of CFC blown foam. (The average surface temperature is $76.6 \mathrm{~F}$ across the solid white line. A second line al a temperature of $71.0 \mathrm{~F}$ is used to define the scale.) 

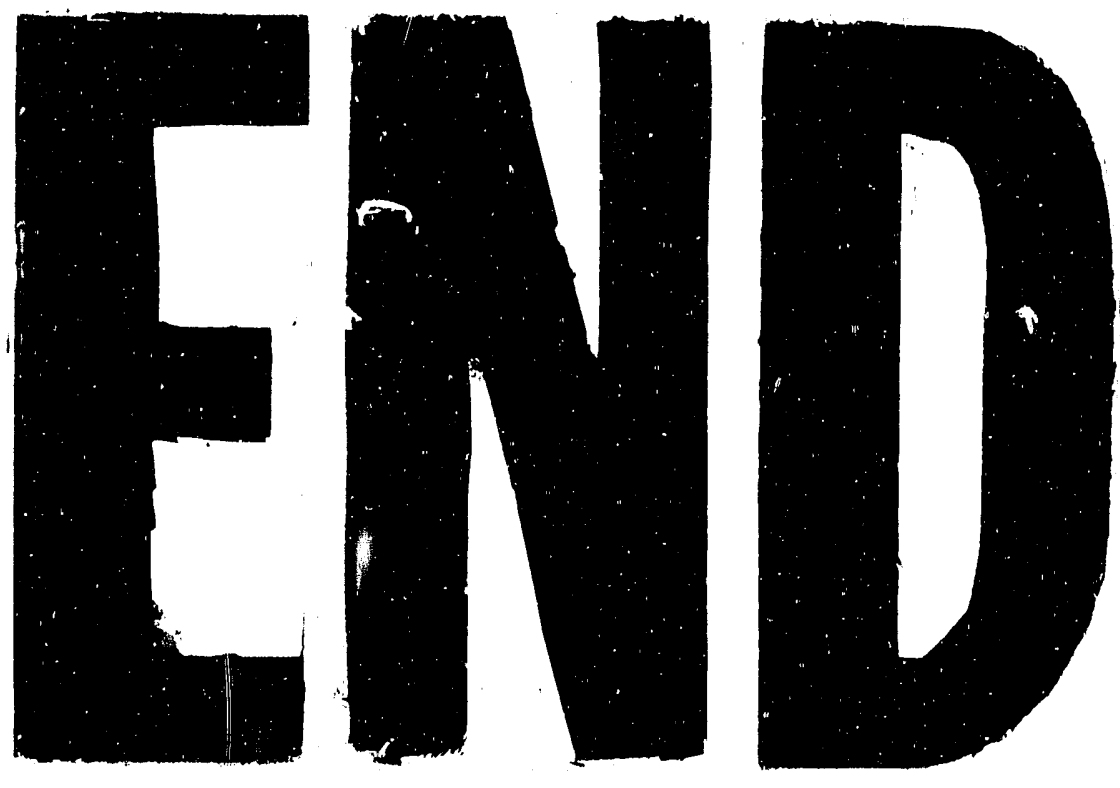

4
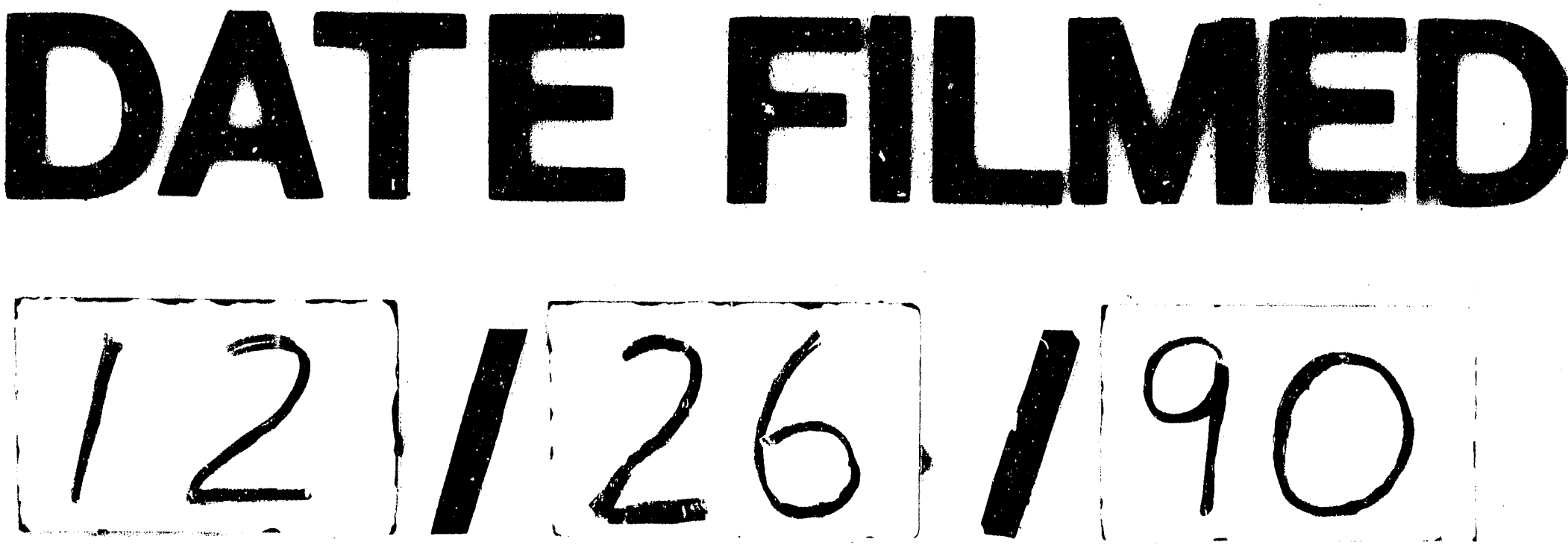


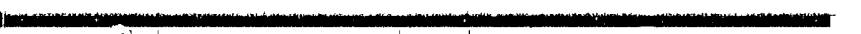

